\title{
Effects of Cocaine on Rat Embryo Development in Vivo and in Cultures
}

\author{
HIBA EL-BIZRI, IAN GUEST, AND DAYA R. VARMA \\ Department of Pharmacology and Therapeutics, McGill University, Montreal, Quebec, Canada H3G 1 Y6
}

\begin{abstract}
Intraperitoneal injections of 6.25, 12.5, 25, 50, and $100 \mu \mathrm{mol} / \mathrm{kg}$ cocaine into pregnant Sprague-Dawley rats once a day from $\mathrm{d} 0$ to 19 of gestation caused a dose-dependent increase in fetal soft tissue malformations, primarily of the genitourinary tract. At $100 \mu \mathrm{mol} / \mathrm{kg}$, all implants were lost and three of the five animals died after six to seven injections. At 50 and $100 \mu \mathrm{mol} / \mathrm{kg}$ but not at lower doses, cocaine caused a small but significant decrease in body weight and food intake. Cocaine did not affect mean fetal and placental weights, although it increased the number of runts and edematous fetuses, and did not cause skeletal malformations. After intraperitoneal injection of $50 \mu \mathrm{mol} / \mathrm{kg}$, the plasma $t_{1 / 2}$ of cocaine was $21 \pm 5 \mathrm{~min}$ and peak plasma concentration $(1682 \pm 260 \mathrm{pmol} / \mathrm{mL}$, measured by HPLC) was achieved in 5-10 min; a lower peak plasma concentration $(486 \pm 103 \mathrm{pmol} / \mathrm{mL})$ was achieved in 20-60 min after s.c. injection. Concentrations of dopamine, epinephrine, and norepinephrine in brains of fetuses or newborn pups $(<12 \mathrm{~h}$ old) of cocaine $(50 \mu \mathrm{mol} / \mathrm{kg})$ treated rats were not significantly elevated. Cocaine injections did not affect gestational duration nor the growth pattern and the locomotor activity of offspring. However, three pups born to one cocaine-treated animal died 20 d after birth. Cocaine inhibited the growth of 10.5-d-old embryos in culture in a concentration-dependent manner and was more toxic than procaine. Approximately $\mathbf{8 0 \%}$ of cocaine was metabolized during a 48-h period in embryo culture medium. It is concluded that cocaine possesses teratogenic potential that may be partly independent of maternal toxicity. (Pediatr Res 29: 187-190, 1991)
\end{abstract}

Cocaine use by pregnant women has been reported to cause a decrease in fetal body weight (1-9), premature delivery (2), genitourinary abnormalities $(10,11)$, cerebral hemorrhage (12), abruptio placentae $(1,2,13,14)$, behavioral abnormalities $(14$, 15), ocular complications (16), and so on. In general, animal studies (17-23) have provided support for the clinical data. However, in most animal studies cocaine was administered s.c. or orally $(17,18,20-24)$, which would result in a lower peak plasma concentration of a longer duration than would occur after equivalent intraperitoneal $(25-27)$ or i.v. (28) doses. We therefore studied the effects of chronic intraperitoneal injections of cocaine on fetal development. Effects of cocaine on the growth of embryos in culture were studied to find out if cocaine's maternal and fetal toxicity could be dissociated. In view of the reported neurochemical effects of cocaine, especially on the dopaminergic system (29), catecholamine levels in brains of

Received April 18, 1990; accepted October 16, 1990.

Correspondence: Dr. D. R. Varma, Department of Pharmacology \& Therapeutics, McGill University, 3655 Drummond Street, Montreal, Quebec, Canada H3G 1 Y6.

Supported by a grant (MA-9726) from the Medical Research Council of Canada. fetuses and newborn pups and locomotor activity of offsprings at 5-7 wk of age were also measured.

\section{MATERIALS AND METHODS}

Animals. Sprague-Dawley virgin female rats (Charles River, St. Constant, Quebec, Canada) weighing 200-225 g were maintained on a 12-h light-dark schedule and fed ad libitum rat food pellets and tap water. For all in vivo studies, females were housed with males during the night. The following morning, spermpositive rats ( $\mathrm{d} 0$ of pregnancy) were placed individually in suspended steel cages and randomly selected to receive once a day between 0900 and $1000 \mathrm{~h}$ either an intraperitoneal injection of saline (controls) or cocaine hydrochloride $(6.25,12.5,25,50$, or $100 \mu \mathrm{mol} / \mathrm{kg}$ ) from $\mathrm{d} 0$ to 19 of gestation and their body weights and food consumption were recorded. Intraperitoneal route of cocaine administration was selected as a convenient and less stressful alternative to chronic i.v. injections primarily because both these routes yield comparable peak plasma cocaine concentrations (25-28). In the absence of obvious signs of pregnancy, corpora lutea were counted to ascertain pregnancy loss. Rats were anesthetized with ether on the morning of d 20 of gestation; live and dead fetuses, number of runts or edematous fetuses, resorption sites, and fetal and placental weights were recorded (30). However, a number of rats treated with saline or $50 \mu \mathrm{mol} / \mathrm{kg}$ cocaine ( $\mathrm{d} 0-20$ of gestation) were allowed to deliver spontaneously and the body weights of offspring were recorded up to $3 \mathrm{wk}$.

Cocaine pharmacokinetics. Pharmacokinetics of cocaine was determined in 13- to $15-\mathrm{d}$ pregnant rats after intraperitoneal ( $n$ $=6)$ and s.c. injection $(n=5)$. For this purpose, a polyethylene cannula (PE30) was placed inside the femoral artery and exteriorized at the back through a s.c. tunnel under ether anesthesia. Approximately $6 \mathrm{~h}$ after surgery and recovery from anesthesia, $50 \mu \mathrm{mol} / \mathrm{kg}$ cocaine was injected intraperitoneally or s.c.; blood samples $(0.25 \mathrm{~mL})$ were collected at $5,10,20,30,45,60,90$, and $120 \mathrm{~min}$ after the injection by heparinized syringes into conical tubes containing $1 \mathrm{mg}$ EDTA and $2 \mathrm{mg}$ NaF. Plasma was immediately separated by centrifugation and stored at $-80^{\circ} \mathrm{C}$

For the extraction of plasma and assay of cocaine and benzoylecgonine (25), $300 \mu \mathrm{L}$ acetonitrile was added to $100 \mu \mathrm{L}$ plasma in a conical $1.5-\mathrm{mL}$ polyethylene tube. The tube was vortexed and centrifuged and the supernatant was transferred to another conical tube to which was added $700 \mu \mathrm{L}$ chloroform:ethanol (4:1) followed by $70 \mu \mathrm{L}$ of $0.1 \mathrm{M} \mathrm{NaHCO}_{3}$. The tube was vortexed for $30 \mathrm{~s}$ and centrifuged. The upper aqueous phase was aspirated off and the remaining organic phase was dried under a stream of nitrogen. To the dry extract was added $30 \mu \mathrm{L}$ of the mobile phase $\left(0.25 \mathrm{M} \mathrm{KH}_{2} \mathrm{PO}_{4}, 25 \%\right.$ acetonitrile, $\left.\mathrm{pH} 2.7\right)$ and the tube was vortexed for $15 \mathrm{~s}$. Standards of cocaine and benzoylecgonine were added to blank rat plasma and subjected to the identical procedure of extraction. Standards and samples were injected into Waters HPLC system (Waters, Mississauga, Ontario). The injection loop was $20 \mu \mathrm{L}$. The mobile phase was delivered to a 
$\mu$ Bondapak C18 reversed-phase column $(300 \times 3.9 \mathrm{~mm}, 10 \mu \mathrm{m}$, Waters) by Waters pump (model 510) at a flow rate of $2 \mathrm{~mL} /$ min. Absorbance was monitored at $235 \mathrm{~nm}$ (Waters UV/VIS detector, model 481) and recorded by Waters data module (model 740). Cocaine and benzoylecgonine were quantitated on the basis of peak areas. The retention time for benzoylecgonine and cocaine were 2.64 and $4.83 \mathrm{~min}$, respectively; the sensitivity limit was $0.5 \mathrm{ng}(1.5 \mathrm{pmol})$ for cocaine and $2 \mathrm{ng}(\sim 7 \mathrm{pmol})$ for benzoylecgonine. The efficiency of extraction was $50 \pm 4 \%$.

Examination of fetal soft tissues and skeleton. Day 20 fetuses were either fixed in Bouin's fluid for internal organ examination by free-hand serial razor sectioning or in ethanol for skeletal examination after staining by Alzarin red (30).

Brain catecholamines. For the assay of catecholamines (31), brains from a number of 20 -d fetuses or newborn pups $(<12 \mathrm{~h}$ old) were removed and cerebella discarded. Brains were homogenized with $2 \mathrm{~mL}$ Tris buffer ( $\mathrm{pH} \mathrm{8.6)}$ and centrifuged at 2000 $\times g$. Catecholamines and the internal standard $(4.5 \mathrm{fmol}), 3,4-$ dihydroxybenzylamine, added to the supernatant were adsorbed to activated alumina and the catecholamines from the alumina were eluted with $150 \mu \mathrm{L}$ of $0.1 \mathrm{M}$ phosphoric acid; an aliquot of this was used for the assay of catecholamines by HPLC (Waters, pump model 510) using WISP (M712, Waters) injector, a BioRad silica-based weak cation-exchange column (195-6002; BioRad Laboratories, Richmond, CA) with a guard column (195-6003) using a $0.07 \mathrm{M}$ citric acid-acetonitrile (88:12) solvent at a flow rate of $1.3 \mathrm{~mL} / \mathrm{min}$. Catecholamines were detected by Waters electrochemical detector (model 460) and quantitated on the basis of the ratio of the peak height generated by authentic amines to that by the internal standard.

Locomotor activity. At 5-7 wk of age, offspring of saline- and cocaine $(50 \mu \mathrm{mol} / \mathrm{kg})$-treated rats were tested for their locomotor activity. Animals were placed singly in transparent plastic cages between 0900 and $1200 \mathrm{~h}$ in a sound-proof room and the frequency of rearing, cage-crossing, and grooming recorded for 20 -s periods with a gap of $10 \mathrm{~s}$ between two recordings for a total duration of $15 \mathrm{~min}$; scores were computed for the $1 \mathrm{st}, 2 \mathrm{nd}$, and 3rd 5-min periods.

Embryo cultures. For these experiments, rats were mated during a 2-h period between 0700 and $0900 \mathrm{~h}$. Embryos (10-12 somite stage) harvested from 10.5 -d pregnant rats were cultured for $48 \mathrm{~h}$ as described previously (32). Saline or increasing concentrations ( $1 \mu \mathrm{M}-1 \mathrm{mM})$ of cocaine or procaine dissolved in saline were added at the start of the culture. At the end of the incubation, embryo size, mortality (absence of heart beat), and protein content (33) were determined.

Statistics. Two means were compared by $t$ test and multiple means by one-way analysis of variance followed by the Bonferroni test for significance. Incidence of fetal mortality or abnormality was compared by $\chi^{2}$ test.

Chemicals. Cocaine hydrochloride was purchased from $\mathrm{BDH}$, Toronto, Canada. Cocaine base and benzoylecgonine were obtained from the Bureau of Drug Abuse, Health and Welfare, Ottawa, Canada. Dopamine, epinephrine, norepinephrine and 3,4-dihydroxybenzylamine were purchased from Sigma Chemical Co., St. Louis, MO. Only high purity grade chemicals were used for the HPLC.

\section{RESULTS}

General effects of cocaine. At 50 to $100 \mu \mathrm{mol} / \mathrm{kg}$ but not at lower doses $(6.25-25 \mu \mathrm{mol} / \mathrm{kg})$, cocaine caused a significant decrease in food intake and body weight gain. After 5 to $6 \mathrm{~d}$ of treatment, animals appeared excited for 15 to $30 \mathrm{~min}$ after receiving cocaine $(6.25$ to $50 \mu \mathrm{mol} / \mathrm{kg})$ injections. After 4 to 5 injections of $100 \mu \mathrm{mol} / \mathrm{kg}$ cocaine, animals exhibited a sudden loss in body weight, appeared lethargic, and three of the five animals died within $15-30 \mathrm{~min}$ after the 6 th or 7 th injection. When an animal died, the death occurred within 15 to $30 \mathrm{~min}$ after injection and was preceded by convulsions. In view of the obvious toxicity, injections of $100 \mu \mathrm{mol} / \mathrm{kg}$ cocaine were discontinued and preimplantation loss was recorded in all five animals. No obvious behavioral differences were noted in d-20 fetuses from cocaine-treated or saline-treated rats. There was no difference in the time for spontaneous delivery $(\sim 21.5 \mathrm{~d})$ of salineand cocaine $(50 \mu \mathrm{mol} / \mathrm{kg})$-treated rats $(n=4$, each group).

Pharmacokinetics of cocaine. The peak plasma concentration of cocaine after intraperitoneal injection was $1682 \pm 260 \mathrm{pmol} /$ $\mathrm{mL}$ and significantly $(p<0.001)$ greater than that $(486 \pm 103$ $\mathrm{pmol} / \mathrm{mL}$ ) after s.c. injection. The peak plasma concentration was observed 5 (in five of six rats) to $10 \mathrm{~min}$ (in one of six rats) after intraperitoneal injections. On the other hand, peak plasma concentration of cocaine was achieved $20-60 \mathrm{~min}$ after s.c. injections (20 min in two, $40 \mathrm{~min}$ in two, and $60 \mathrm{~min}$ in one of five rats). The plasma $t_{1 / 2}$ of cocaine after intraperitoneal injection was $21 \pm 5 \mathrm{~min}$. The elimination phase of cocaine after s.c. injection was not discernible and plasma $t_{1 / 2}$ could not be derived. Although benzoylecgonine peaks were observed in most sample runs, their concentrations were too low to permit quantitation.

Maternal and fetal effects of cocaine. These effects are described in Tables 1 and 2. No skeletal abnormalities were recorded in fetuses of cocaine-treated animals and data are not shown. The body weight of d-20 fetuses $(n=170)$ of saline-treated rats was $3.6 \pm 0.1 \mathrm{~g}$. Fetuses $(n=160)$ of rats treated with $50 \mu \mathrm{mol} / \mathrm{kg}$ cocaine could be subdivided as overweight $(>4 \mathrm{~g}, n=32)$, underweight $(<3.2 \mathrm{~g}, n=23)$, and normal weight $(3.2-4 \mathrm{~g}, n=$ 95). However, there was no significant difference in the mean body weight of all fetuses of saline- and cocaine-treated animals.

Brain catecholamines. Although the dopamine, epinephrine, and norepinephrine concentrations in brains (whole brain minus the cerebellum) of 20-d gestational age fetuses and newborn pups of cocaine-treated rats were higher than the corresponding values for the saline-treated group, the differences were not significant (Table 3).

Offspring growth pattern and locomotor activity. Body weights of offspring born to saline- and cocaine $(50 \mu \mathrm{mol} / \mathrm{kg})$-treated rats were, respectively, $6.3 \pm 0.1$ and $5.9 \pm 0.3 \mathrm{~g}$ on $\mathrm{d} 1,16.4 \pm 0.3$ and $14.9 \pm 0.5 \mathrm{~g}$ on $\mathrm{d} 7,30.7 \pm 0.8$ and $29.2 \pm 0.5 \mathrm{~g}$ on $\mathrm{d} 14$ and $49.2 \pm 0.6$ and $49.2 \pm 0.5 \mathrm{~g}$ on $\mathrm{d} 21$ after birth. There was no significant difference in the body weights and locomotor activity (Table 4 ) of the offspring of rats treated during pregnancy with saline or $50 \mu \mathrm{mol} / \mathrm{kg}$ cocaine.

Effect of cocaine on embryos in culture. Cocaine caused concentration-dependent inhibition of embryo development in culture and was lethal (as judged by the absence of heart beat) to all embryos at a concentration of $300 \mu \mathrm{M}$ (Fig. 1). Cocaine was approximately 10 -fold more toxic than procaine. The concentration of cocaine at the end of the 48 -h culture period was $18 \pm$ $2 \%$ of the initial concentration.

\section{DISCUSSION}

Most workers studying cocaine teratogenicity administered the drug s.c. $(17,21-23)$ or orally $(18,20)$, which would result in a slower absorption and, in turn, a relatively low peak plasma concentration. Results of this study and a comparison of pharmacokinetic data from other studies $(25-28,34)$ indicate that this is in fact the case. This may explain why the highest dose of $100 \mu \mathrm{mol} / \mathrm{kg} / \mathrm{d}$ used in our study was far more toxic than 120 to $270 \mu \mathrm{mol} / \mathrm{kg}$ administered s.c. by other workers $(17,21-23)$ and why several investigators found little or no effect of s.c. injections of 60 to $120 \mu \mathrm{mol} / \mathrm{kg}$ cocaine $(17,21-23)$, whereas we observed significant maternal and fetal toxicity at 25 - to 50 $\mu \mathrm{mol} / \mathrm{kg}$ dose levels. It would appear that high concentrations of cocaine for shorter durations are more relevant from a toxicologic point of view (and perhaps better mimic abuse by humans) than lower sustained concentrations.

Our study shows that prenatal exposure to cocaine causes dose-dependent maternal and fetal toxicity. Fetal abnormalities such as urogenital malformation and cerebral hemorrhage are in 
Table 1. Maternal and fetal effects of cocaine in rats*

\begin{tabular}{|c|c|c|c|c|c|c|}
\hline \multirow[b]{2}{*}{ Variables } & \multicolumn{6}{|c|}{ Cocaine $(\mu \mathrm{mol} / \mathrm{kg})$} \\
\hline & 0 & 6.25 & 12.5 & 25 & 50 & 100 \\
\hline$n$ & 13 & 6 & 6 & 6 & 17 & 5 \\
\hline Day 20 body wt (g) & $375 \pm 6$ & $368 \pm 8$ & $374 \pm 8$ & $357 \pm 10$ & $357 \pm 6 \dagger$ & \\
\hline Food intake $(\mathrm{g} / \mathrm{d})$ & $23.2 \pm 0.2$ & $23.7 \pm 0.4$ & $22.6 \pm 0.4$ & $22.1 \pm 0.5$ & $20.5 \pm 0.4 \dagger$ & $16 \pm 0.4 \dagger$ \\
\hline Maternal death $(n)$ & 0 & 0 & 0 & 0 & $2 \dagger$ & $3 \dagger$ \\
\hline Placental wt (mg) & $465 \pm 14$ & $440 \pm 21$ & $431 \pm 17$ & $476 \pm 13$ & $438 \pm 7$ & \\
\hline Edematous fetuses $(n)$ & $0 / 170$ & $0 / 79$ & $0 / 80$ & $5 / 63$ & $15 / 160$ & \\
\hline Runts $(n)$ & $0 / 170$ & $2 / 79$ & $3 / 89 \dagger$ & $2 / 63$ & $12 / 160 \dagger$ & \\
\hline Resorptions $(n)$ & 6 & $9 \dagger$ & 1 & 5 & $12 \dagger$ & \\
\hline
\end{tabular}

* Cocaine was injected intraperitoneally once a day from d 0 to 19 of gestation inclusive and animals were killed on d 20; 0 dose refers to saline injections.

$\dagger$ Significantly $(p<0.05)$ different from the corresponding value for the saline-treated animals; data are either means \pm SEM or total numbers.

Table 2. Fetal abnormalities after daily intraperitoneal injections of cocaine in rats from d 0 to 19 of gestation

\begin{tabular}{lccccc}
\hline & \multicolumn{5}{c}{ Cocaine $(\mu \mathrm{mol} / \mathrm{kg})$} \\
\cline { 2 - 6 } Variables* & 0 & 6.25 & 12.5 & 25 & 50 \\
\hline Litters examined $(n)$ & 13 & 6 & 6 & 5 & 12 \\
Fetuses examined $(n)$ & 37 & 19 & 21 & 18 & 34 \\
Enlarged bladder & 0 & $3 \dagger$ & $6 \dagger$ & $5 \dagger$ & $9 \dagger$ \\
Hydronephrosis & 2 & $7 \dagger$ & $8 \dagger$ & $8 \dagger$ & $16 \dagger$ \\
Cerebral hemorrhage & 0 & 0 & 0 & 1 & 4 \\
Total abnormal fetuses $(n)$ & 2 & $8 \dagger$ & $8 \dagger$ & $9 \dagger$ & $20 \dagger$ \\
\hline
\end{tabular}

* Refer to fetuses on d 20 of gestation.

$\dagger$ Significantly $(p<0.05)$ different from corresponding values for saline-treated ( 0 dose of cocaine) animals.

Table 3. Effect of prenatal exposure to cocaine on brain catecholamines of fetuses and newborn pups of rats.

\begin{tabular}{lccc}
\hline Group* & Dopamine & Epinephrine & Norepinephrine \\
\hline Fetus-saline & $184 \pm 42.2 \dagger$ & $5.0 \pm 1.4$ & $147 \pm 37.9$ \\
Fetus-cocaine & $218 \pm 32.7$ & $20.5 \pm 8.5$ & $163 \pm 20.9$ \\
Newborn-saline & $196 \pm 24.2$ & $28.6 \pm 7.9$ & $311 \pm 28.4$ \\
Newborn-cocaine & $242 \pm 18.9$ & $38.0 \pm 11.3$ & $352 \pm 14.8$ \\
\hline
\end{tabular}

* Day 20 fetuses or newborn pups ( $<12 \mathrm{~h}$ old) from rats injected with saline or $50 \mu \mathrm{mol} / \mathrm{kg}$ cocaine from d 0 to 19 of gestation; the treatment is indicated in the first column after the hyphen.

$\dagger$ Values are $\mathrm{fmol} / \mathrm{mg}$ brain protein, mean \pm SEM; $n=5-8$.

Table 4. Locomotor activity of offspring of rats treated with saline or cocaine $(50 \mu \mathrm{mol} / \mathrm{kg})$ intraperitoneally from d 0 to 20 of gestation*

\begin{tabular}{llrrr}
\hline $\begin{array}{l}\text { Offspring of rats } \\
\text { treated with }\end{array}$ & Activity & 1st 5 min & 2nd 5 min & 3rd 5 min \\
\hline Saline & Cage crossing & $6.4 \pm 0.5$ & $2.6 \pm 0.3$ & $1.1 \pm 0.3$ \\
Cocaine & Cage crossing & $7.3 \pm 0.9$ & $3.3 \pm 0.5$ & $1.5 \pm 0.4$ \\
Saline & Rearing & $24.3 \pm 0.4$ & $13.3 \pm 1.4$ & $6.3 \pm 1.1$ \\
Cocaine & Rearing & $21.4 \pm 1.8$ & $16.1 \pm 1.7$ & $10.1 \pm 1.5$ \\
Saline & Grooming & $1.3 \pm 0.5$ & $2.2 \pm 0.5$ & $1.9 \pm 0.6$ \\
Cocaine & Grooming & $0.9 \pm 0.3$ & $2.5 \pm 0.6$ & $1.9 \pm 0.5$ \\
\hline
\end{tabular}

* Activity was recorded at $5-7 \mathrm{wk}$ of age and is shown as the mean \pm SEM of 1020 -s observation periods during the $1 \mathrm{st}$, 2nd, and $3 \mathrm{rd} 5 \mathrm{~min}$. Data are derived from 17-18 offspring in each group from four separate litters.

agreement with clinical data (10-12). On the other hand, certain effects of prenatal exposure to cocaine in humans such as premature delivery and a decrease in fetal weight (1-9) were not observed in this study; in this sense, rat may not be a perfect
COCAINE
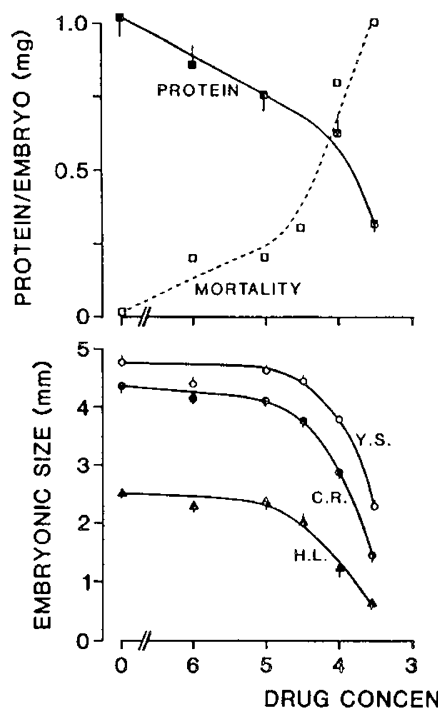

Fig. 1. Effects of cocaine and procaine on the development of rat embryos in culture. Each data point represents mean \pm SEM of five to 10 embryos. Y.S., yolk sac diameter; C.R., crown rump; and H.L., head length; absence of heart beats denoted mortality. Significant $(p<0.05)$ differences (not shown in the figure to avoid overcrowding): effects of cocaine on protein content and mortality were significant at all concentrations; procaine significantly inhibited protein content at $>10^{-5} \mathrm{M}$ and was lethal to embryos only at $10^{-3} \mathrm{M}$; embryonic sizes at $>10^{-5}$ cocaine and $>10^{-4}$ procaine are significantly different from the corresponding values at 0 drug (saline) concentration.

model for the study of cocaine teratogenicity. The lack of difference in body weights of fetuses from saline- and cocaine-treated rats (Table 1) is similar to data of other workers using a rodent model (17, 20-23); however, this may not represent the true picture because some litters of cocaine-treated rats were underweight and some overweight and edematous. Determinants of these variable effects of cocaine on fetal weight are not apparent from our studies.

The lack of a significant effect of prenatal exposure to cocaine on fetal and newborn brain catecholamines (Table 3) and on the locomotor activity of offspring (Table 4) is in conformity with other data (24). Also, chronic cocaine abuse in humans was found to be without effects on circulating catecholamines and lymphocyte adrenoceptors (35). On the other hand, an increase in motor activity of rat offspring exposed to cocaine in utero was found by others $(22,23)$ for a temporary period during suckling but not after weaning. 
Our data showing that prenatal exposure to cocaine did not affect the growth pattern of pups is in accordance with other reports using a rodent model $(20,21)$. On the other hand, death of three pups in one litter from a cocaine-treated mother may be of relevance; we did not encounter any deaths during weaning in a small number of control animals in this series nor in more than 100 litters over the last few years.

It has been argued that the teratogenic effects of cocaine may be due to its ability to decrease placental blood flow and fetal oxygenation $(21,36,37)$. Although this is possible, our studies with embryo cultures in vitro suggest that cocaine can exert direct fetal toxicity, albeit at concentrations much higher than could have been achieved in vivo at the highest dose of $50 \mu \mathrm{mol} / \mathrm{kg}$ used in our studies. Because procaine was also embryotoxic although less so than cocaine, it may be a common property of local anesthetics and the underlying mechanism may be independent of interactions with catecholamines.

In conclusion, this study demonstrates teratogenic potential of prenatal exposure to cocaine and shows that fetal toxicity of cocaine may involve a maternal and a direct fetal component.

\section{REFERENCES}

1. Bingol N, Fuchs M, Diaz V, Stone RK, Gromisch DS 1987 Teratogenicity of cocaine in humans. J Pediatr 1 10:93-96

2. Cherukuri R, Minkoff H, Feldman J, Parekh A, Glass L 1988 A cohort study of alkaloid cocaine ("crack") in pregnancy. Obstet Gynecol 72:147-151

3. Chouteau M, Namerow PB, Leppert P 1988 The effect of cocaine abuse on birth weight and gestational age. Obstet Gynecol 72:351-354

4. Fulroth R, Phillips B, Durand DJ 1989 Perinatal outcome of infants exposed to cocaine and/or heroin in utero. Am J Dis Child 143:905-910

5. Hadeed AJ, Siegel SR 1989 Maternal cocaine use during pregnancy: effect on the newborn. Pediatrics 84:205-210

6. MacGregor SN, Keith LG, Chasnoff IJ, Rosner MA, Chisum GM, Shaw P, Minogue JP 1987 Cocaine use during pregnancy: adverse perinatal outcome. Am J Obstet Gynecol 157:686-690

7. Oro AS, Dixon SD 1987 Perinatal cocaine and methamphetamine exposure: maternal and neonatal correlates. J Pediatr 111:571-578

8. Ryan L, Ehrlich S, Finnegan L 1987 Cocaine abuse in pregnancy: effects on the fetus and newborn. Neurotoxicol Teratol 9:295-299

9. Zuckerman B, Frank DA, Hingson R, Amaro H, Levenson SM, Kayne H, Parker S, Vinci R, Aboagye K, Fried LE, Cabral H, Timperi R, Bauchner H 1989 Effects of maternal marijuana and cocaine use on fetal growth. N Engl J Med 320:762-768

10. Chasnoff IJ, Chisum GM, Kaplan WE 1988 Maternal cocaine use and genitourinary tract malformations. Teratology 37:201-204

11. Chavez GF, Mulinare J, Cordero JF 1989 Maternal cocaine use during early pregnancy as a risk factor for congenital anomalies. JAMA 262:795-798

12. Chasnoff IJ, Bussey ME, Savich R, Stack CM 1986 Perinatal cerebral infarction and maternal cocaine use. J Pediatr 108:456-459

13. Acker D, Sachs BP, Tracey KJ 1983 Abruptio placentae associated with cocaine use. Am J Obstet Gynecol 146:220-221

14. Chasnoff IJ, Burns WJ, Schnoll SH, Burns KA 1985 Cocaine use in pregnancy. N Engl J Med 313:666-669

15. Doberczak TM, Shanzer S, Senie RT, Kandall SR 1988 Neonatal neurologic and electroencephalographic effects of intrauterine cocaine exposure. J Pediatr 113:354-358

16. Isenberg SJ, Spierer A, Inkelis SH 1987 Ocular signs of cocaine intoxication in neonates. Am J Ophthalmol 103:211-214

17. Church MW, Dintcheff BA, Gessner PK 1988 Dose-dependent consequences of cocaine on pregnancy outcome in the Long-Evans rat. Neurotoxicol Teratol 10:51-58

18. Dow-Edwards DL 1989 Long-term neurochemical and neurobehavioral consequences of cocaine use during pregnancy. Ann NY Acad Sci 562:280-289

19. Fantel AG, Macphail BJ 1982 The teratogenicity of cocaine. Teratology 26:1719

20. Hutchings DE, Fico TA, Dow-Edwards DL 1989 Prenatal cocaine: maternal toxicity, fetal effects and locomotor activity in rat offspring. Neurotoxicol Teratol 11:65-69

21. Mahalik MP, Gautieri RF, Mann DE 1984 Mechanisms of cocaine-induced teratogenesis. Res Commun Subst Abuse 5:279-302

22. Smith RF, Mattran KM, Kurkjian MF, Kurtz SL 1989 Alterations in offspring behavior induced by chronic prenatal cocaine dosing. Neurotoxicol Teratol 11:35-38

23. Spear LP, Kirstein CL, Bell J, Yoottanasumpun V, Greenbaum R, O'Shea J, Hoffmann H, Spear NE 1989 Effects of prenatal cocaine exposure on behavior during the early postnatal period. Neurotoxicol Teratol 11:57-63

24. Fung YK, Reed JA, Lau YS 1989 Prenatal cocaine exposure fails to modify neurobehavioral responses and the striatal dopaminergic system in newborn rats. Gen Pharmacol 20:689-693

25. Benuck M, Lajtha A, Reith MEA 1987 Pharmacokinetics of systemically administered cocaine and locomotor stimulation in mice. J Pharmacol Exp Ther 243:144-149

26. DeVane CL, Simpkins JW, Miller RL, Braun SB 1989 Tissue distribution of cocaine in the pregnant rat. Life Sci 45:1271-1276

27. Shah NS, May DA, Yates JD 1980 Disposition of levo- $\left[{ }^{3} \mathrm{H}\right]$ cocaine in pregnant and nonpregnant mice. Toxicol Appl Pharmacol 53:279-284

28. Nayak PK, Misra AL, Mule SJ 1976 Physiological disposition and biotransformation of $\left[{ }^{3} \mathrm{H}\right]$ cocaine in acutely and chronically treated rats. J Pharmacol Exp Ther 196:556-569

29. Bozarth MA 1989 New perspectives on cocaine addiction: recent findings from animal research. Can J Physiol Pharmacol 67:1158-1167

30. Varma DR, Ferguson JS, Alarie Y 1987 Reproductive toxicity of methyl isocyanate in mice. J Toxicol Environ Health 21:265-275

31. Shohami E, Segal M, Jacobowitz DM 1983 Application of high-performance liquid chromatography with electrochemical detection to the determination of catecholamines in microdissected regions of the rat brain. $\mathbf{J}$ Neurosci Methods 8:275-281

32. Varma DR, Guest I, Smith S, Mulay S 1990 Dissociation between maternal and fetal toxicity of methyl isocyanate in mice and rats. J Toxicol Environ Health $30: 1-14$

33. Lowry OH, Roseborough NJ, Farr AL, Randall RJ 1951 Protein determination with Folin phenol reagent. J Biol Chem 193:265-275

34. Dow-Edwards D, Fico TA, Osman M, Gamagaris Z, Hutchings DE 1989 Comparison of oral and subcutaneous routes of cocaine administration on behavior, plasma drug concentration and toxicity in female rats. Pharmacol Biochem Behav 33:167-173

35. Ward SLD, Bautista DB, Buckley S, Schuetz S, Wachsman L, Bean X, Warburton D 1989 Circulating catecholamines and adrenoceptors in infants of cocaine-abusing mothers. Ann NY Acad Sci 562:349-351

36. Moore TR, Sorg JS, Miller L, Key TC, Resnik R 1986 Hemodynamic effects of intravenous cocaine on the pregnant ewe and fetus. Am J Obstet Gynecol $155: 883-888$

37. Woods JR, Plessinger MA, Clark KE 1987 Effect of cocaine on uterine blood flow and fetal oxygenation. JAMA 257:957-961 